\title{
Patterns of forensic practice
}

\author{
Harold Merskey DM FRCP FRCPC FRCPsych
}

$\mathrm{F}^{\mathrm{s}}$

Torensic pain medicine has provided an interesting survey of medico-legal practice patterns among pain specialists (1). Members of the New England Pain Association responded to a 20-item questionnaire addressing specific areas of practice including the completion of disability forms, letters, reports to lawyers, depositions, testimony in court, record reviews and return-to-work forms. Respondents were asked to distinguish the medico-legal activities for their patients from those that occurred for third parties.

The participants who responded included pain specialists from a range of disciplines represented by the membership of this regional pain society. The response rate was $67 \%$ with a total of 144 surveys returned.

Among the $67 \%, 72 \%$ of pain specialists had engaged in some form of medico-legal work within the past year. Of these 100 responders, $19 \%$ were identified as practicing medicine as pain physicians $(\mathrm{n}=28)$ and $19 \%$ as anesthesiologists. Psychology or psychiatry accounted for $15 \%$; dentistry/oral surgery, $12 \%$; other physicians/specialties, $10 \%$; nursing, $10 \%$; physiotherapy or occupational therapy, $6 \%$; and other types of practice, $9 \%$. All these figures should probably be reduced by one-third to allow for the fact that one-third of the physicians approached overall did not respond, and must be assumed to be those who are least interested in data of this type, and therefore, least likely to be accepting or providing forensic work. Even so, the report shows high rates of involvement in medicolegal activities largely among the pain health care practitioners for their patients. Thus, using the uncorrected figures, 55\% engaged in their role solely as the 'treating clinician' and $41 \%$ worked both as treating clinicians and as experts for third parties (eg, attorneys, insurance carriers). Only 4\% restricted their work solely to serve as independent experts to third parties, and these generally included pain specialists who reported relatively high volumes of medico-legal practices. For example, the article reportedexamples of individuals with medico-legal case loads exceeding 500 cases a year.
More than half those responding provided letters or reports to attorneys and many completed disability or return-to-work forms. Forty per cent had been involved in a deposition. 'Depositions' do not seem to be common or employed in Canada. We have affidavits; sworn testimony that is often not cross examined, and 'examination for discovery'. Pain practitioners are generally not involved in examinations for discovery which involve questioning of the witness under oath in the presence of his or her own lawyer and with full recording, but not in the presence of any other parties and without a judge.

Twenty-four per cent of physicians had 'provided testimony' for their own patients on at least one occasion within the previous year. As well, $24 \%$ to $45 \%$ of nonphysicians have also engaged in a range of other specific medico-legal activities. Unfortunately, as the authors point out, the survey did not collect information on the different settings in which testimony was provided such as videotape testimony, testimony in court, mediations or administrative hearings, for their patients.

The authors of this article were concerned because of the lack of awareness of ethical guidelines for medico-legal work among pain physicians. We might suspect that very few pain practitioners are aware of any specialized ethical guidelines with respect to pain and forensic work, but we are all keenly aware of the existence of general guidelines and of the need to put the interest of the patient first in all medical relationships except for third party matters. The authors of the article seem to feel that there was a need to develop specific pain practitioner guidelines with regard to ethics. Personally speaking, I do not know if the case has been argued for or against special discipline-specific requirements for pain testimony in addition to the general requirements in medicine.

\section{REFERENCE}

1. Kulich RJ, Driscoll S, Scrivoni SJ, Mehta N. A survey of medico-legal practice patterns among pain specialists. Pain Med 2004,5:98-103. 


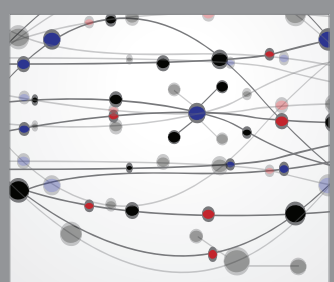

The Scientific World Journal
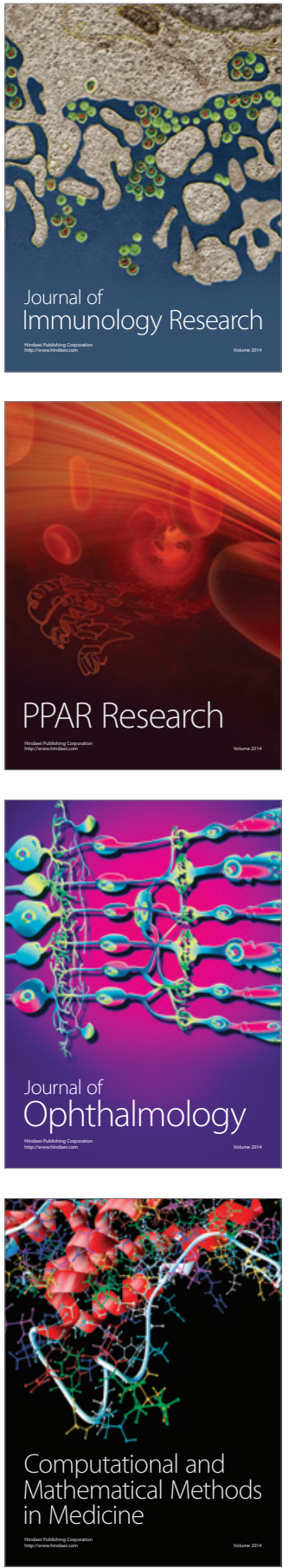

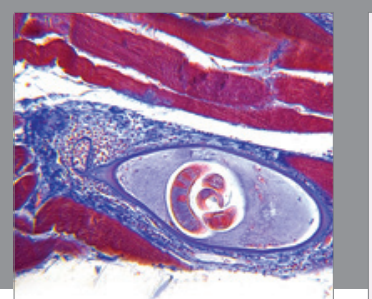

Gastroenterology Research and Practice

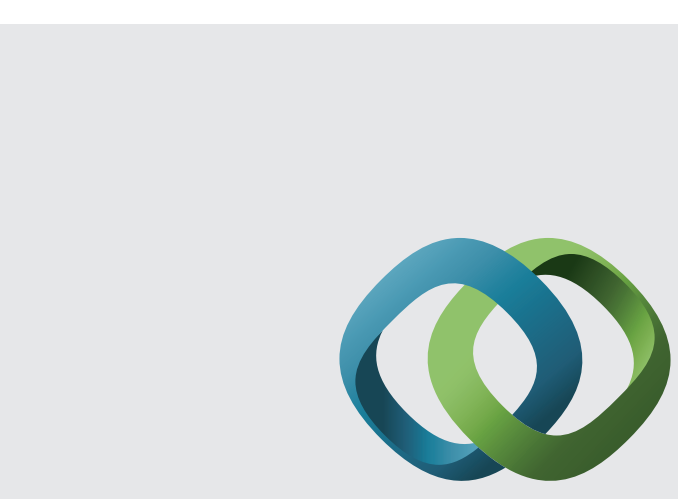

\section{Hindawi}

Submit your manuscripts at

http://www.hindawi.com
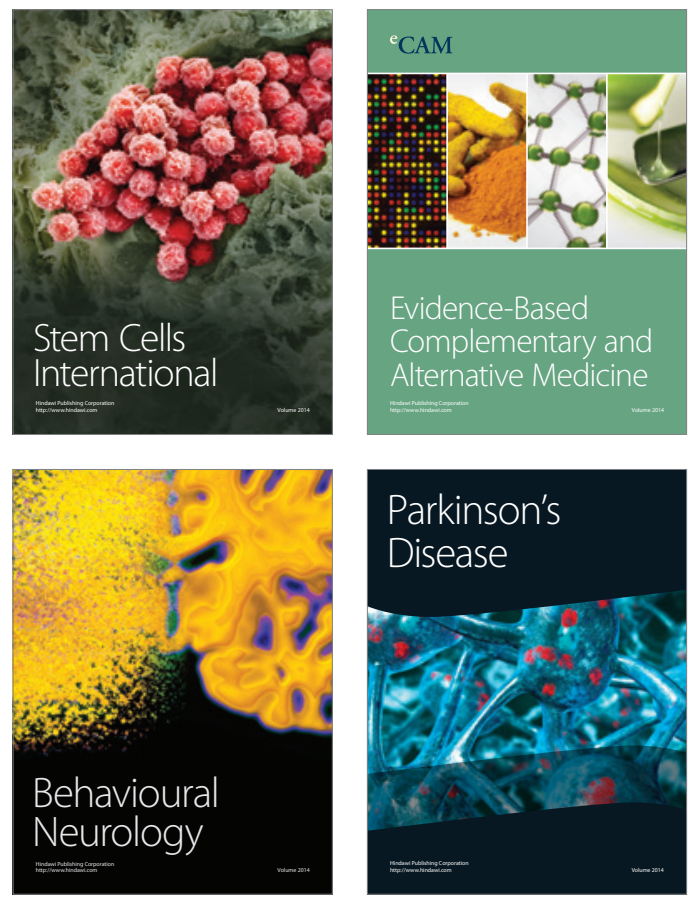
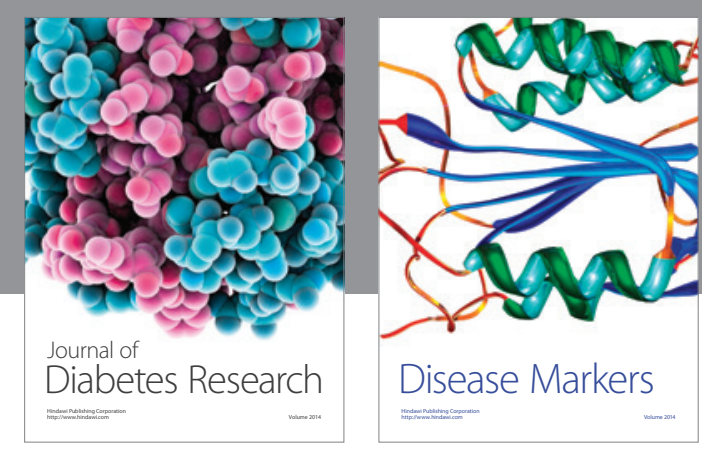

Disease Markers
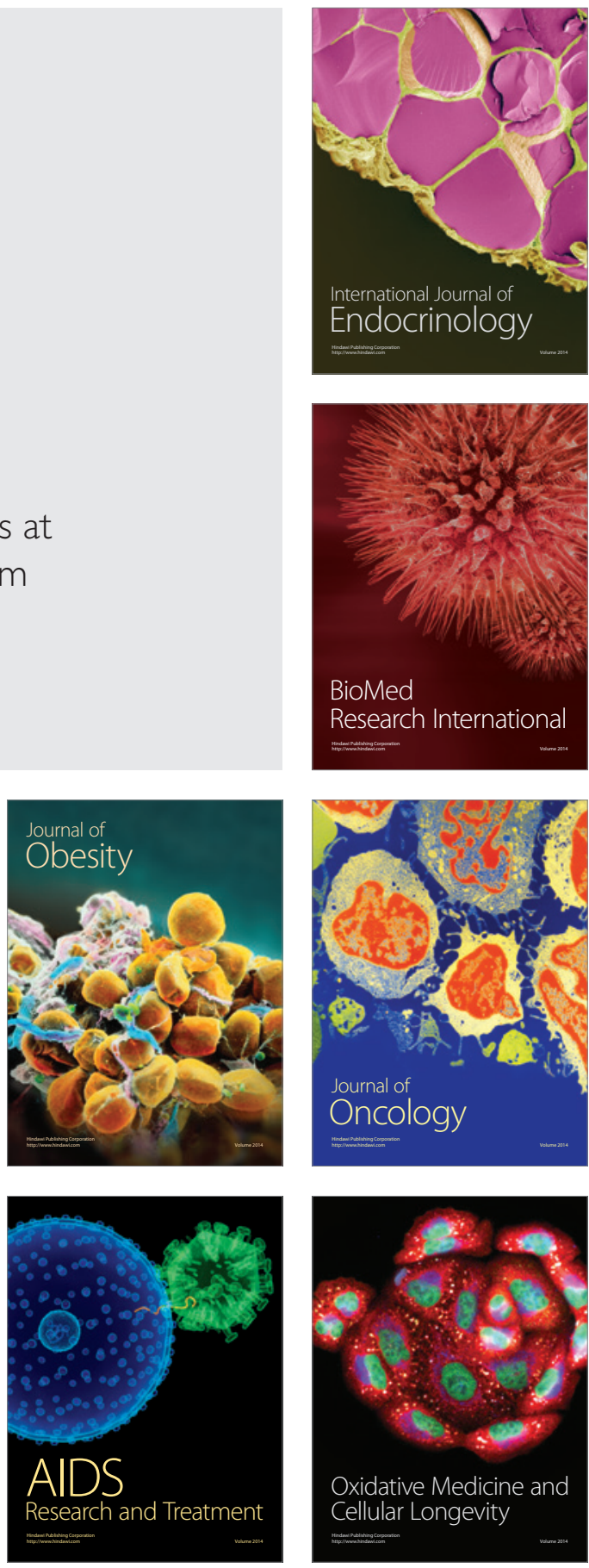